\title{
Acute Psychotic Syndrome in a Male Adolescent with Succinic Semialdehyde Dehydrogenase Deficiency
}

\author{
Konstantinos Kontoangelos ${ }^{1,2} \bowtie$, Helen Lazaratou' ${ }^{1}$, Marina Economou ${ }^{1,2}$, \\ Dimitris Dikeos ${ }^{1}$, and Charalambos Papageorgiou ${ }^{1,2}$ \\ ${ }^{11}$ st Department of Psychiatry, Medical School, National \& Kapodistrian University of Athens, Eginition Hospital, Athens, Greece \\ ${ }^{2}$ University Mental Health Research Institute, Athens, Greece
}

SSADH deficiency (Semialdehyde Dehydrogenase Deficiency) is inherited in an autosomal recessive fashion, caused by an error in a single DNA gene. Being a recessive disorder, the disease can only occur when a person has two copies of the gene and thus it can only be inherited if both parents are carriers of the gene. It is believed that the genetic basis for SSADH deficiency resides in the human ALDH5A1 gene which maps to chromosome 6p22. ${ }^{1}$ The symptoms of SSADH deficiency fall into three primary categories: neurological, psychiatric, and ocular. The most constant features are developmental delay, hypotonia and intellectual disability. Nearly half of the patients manifest ataxia, behavior problems, seizures, and hyporeflexia. ${ }^{2}$

This is a case of a young male adolescent who was diagnosed with a mild intellectual disability and psychomotor developmental delay; he walked at 3 years of age, spoke at the age of 4 years, and joined kindergarten as a 6-year-old and the primary school as an 8-year-old. At the age of two years the diagnosis of SSADH deficiency was established after a sample of lymphocytes was sent to the University Hospital VU Department of Pediatrics in Amsterdam where specific examinations were carried out. He followed a program of speech therapy and physiotherapy. In the school he socialized well and he finished the 9-year obligatory education, having the benefit of special support. At the age of 16 he showed psychomotor agitation and insomnia and suddenly ran away. He wandered around for two days and finally the police found him in a park. He was quite violent, kicking and swearing.

\footnotetext{
Received: November 1, 2018 Revised: November 21, 2018

Accepted: December 5, 2018

$\square$ Correspondence: Konstantinos Kontoangelos, MD

1st Department of Psychiatry, Medical School, National \& Kapodistrian University of Athens, Eginition Hospital, 74 Vas. Sofias Avenue, 11528 Athens, Greece Tel: +0030-210-7289409, Fax: +0030-210-7640111, E-mail: kontange@hol.gr

(c) This is an Open Access article distributed under the terms of the Creative Commons Attribution Non-Commercial License (https://creativecommons.org/licenses/by$\mathrm{nc} / 4.0$ ) which permits unrestricted non-commercial use, distribution, and reproduction in any medium, provided the original work is properly cited.
}

He complained about auditory hallucinations and specifically that he was hearing voices urging him to "take a knife and harm his family or other people." He was hospitalized for about twenty days and he left the hospital under medication with quetiapine $75 \mathrm{mg}$ p.o. and risperidone $3 \mathrm{mg}$ p.o. per day. He currently attends occupational workshops in a foundation for children with intellectual disabilities. At present he has no psychotic symptomatology, but residual symptoms include very limited social functioning and a dysphoric feeling (constantly complaining about everything).

In this case report a young adolescent suffering from SSADH deficiency with developmental delay and learning disabilities developed psychotic symptoms. Patients with SSADH deficiency very often have learning disabilities, ${ }^{3}$ but hallucinations are rarer. Hallucinations practically never appear before adolescence and they seem to be paradoxical in SSADH deficiency, since gamma-amino butyric acid (GABA) whose amount is increased and GHB ( $\gamma$-hydroxybutyrate), an unusual compound which also accumulates as a result of the disorder, exhibit antipsychotic effects by inhibiting dopamine release. ${ }^{4}$ Patients suffering from SSADH deficiency usually manifest other neuropsychiatric disorders such as behavioral problems, inattention, hyperactivity, anxiety, obsessive-compulsive symptoms, aggression, pervasive developmental disorder, autistic behavior and sleep disturbances. Neurotoxicity is considered to be one of the pathophysiological mechanisms which cause these impairments but also the surplus of GABA might influence the synaptic inhibition and the progress of long term potentiation (LTP). ${ }^{5}$ The present case report, in conjunction with the previous literature, highlights the importance of considering rare metabolic diseases and genetically inherited errors when diagnosing patients with development of psychosis on a substrate of pre-existing learning disabilities.

\section{REFERENCES}

1. Gibson KM, Schor DS, Gupta M, Guerand WS, Senephansiri H, Burl- 
ingame TG, et al. Focal neurometabolic alterations in mice deficient for succinate semialdehyde dehydrogenase. J Neurochem 2002;81:71-79.

2. Pearl PL, Novotny EJ, Acosta MT, Jakobs C, Gibson KM. Succinic semialdehyde dehydrogenase deficiency in children and adults. Ann Neurol 2003;54(Suppl 6):S73-S80.

3. Gibson KM, Christensen E, Jakobs C, Fowler B, Clarke MA, Hammersen G, et al. The clinical phenotype of succinic semialdehyde de- hydrogenase deficiency (4-hydroxybutyric aciduria): case reports of 23 new patients. Pediatrics 1997;4:567-574.

4. Maitre M. The gamma-hydroxybutyratesignalling system in brain: organization and functional implications. Prog Neurobiol 1997;51:337-361.

5. Knerr I, Gibson KM, Jakobs C, Pearl PL. Neuropsychiatric morbidity in adolescent and adult succinic semialdehyde dehydrogenase deficiency patients. CNS Spectr 2008;13:598-605. 